\title{
A DIVULGAÇÃO DO PATRIMÔNIO ARQUEOLÓGICO EM CASTILLA Y LEÓN (ESPANHA):O DESAFIO DOS ESPAÇOS DIVULGATIVOS
}

\author{
Ana Maria Mansilla Castaño*
}

\begin{abstract}
Resumo: 0 interesse pelo patrimônio e particularmente pela sua divulgação é um fenômeno global. Na Espanha isto acontece nas últimas décadas. Neste artigo se analisa o caso de uma Comunidade Autônoma, Castilla y Leon, caracterizada pela riqueza e diversidade do seu patrimônio. 0 principal objetivo deste texto é a dimensão discursiva dos diferentes espaços divulgativos, museus, sítios arqueológicos e centros de interpretação, visando a avaliação de suas características e inter-relações. Enfatiza os pontos fracos e as alternativas teóricas e práticas.
\end{abstract}

Palavras chave: patrimônio arqueológico - divulgação - Espanha Castilla y León

\section{J ustificativa e contextualização da pesquisa}

Sob o ponto de vista disciplinar e social é cada vez mais evidente o crescente protagonismo da divulgação arqueológica (Ballart 1997, Ballart e Juan 2001), o que se vem concretizando no maior número de artigos dedicados ao tema nas revistas especializadas, na presença em congressos e cursos de todo tipo, e claro, no significativo número de projetos de pesquisa arqueológica que incluem, de uma forma ou outra, um apartado específico sobre este tema, embora não tenha atingido ainda esse protagonismo na formação universitária. Mas este contexto não tem vindo acompanhado de uma pesquisa no mesmo nível. Isto é, na Espanha em geral a divulgação se tem man-

(*) Escola Oficina de Restauro de Salvador anamansillac@oi.com.br tido como um campo marcado pela ação mais do que pela reflexão crítica.

Esta proposta centra-se numa Comunidade Autónoma, Castilla y León, especialmente atrativa por diversas razões: em primeiro lugar, por o significativo número de sítios arqueológicos visitáveis, de caráter marcante, alguns deles Patrimônio da Humanidade como Atapuerca (Burgos) ou Las Médulas (León); em segundo lugar, pela ativa política de divulgação arqueológica que se vem realizando nela e, em terceiro lugar, por não ser nenhuma das comunidades históricas, como são Cataluña ou Galicia, cuja dinâmica neste âmbito tem sido bastante diferente, com uma maior projeção e tradição, em alguns casos.

A Comunidade de Castilla y León pode ser considerada paradigmática do papel que tem o patrimônio na sociedade atual, pois são coincidentes nela muitos dos problemas e potencialidades que afetam o patrimônio em sua relação como o turismo, a econo- 
mia, as políticas, o mercado de trabalho, a pesquisa e os pesquisadores. Apenas recentemente o patrimônio arqueológico começa a mergulhar nesta densa rede de relações e conflitos de interesses. Em resumo, é agora que começa a adquirir uma maior visibilidade.

A Comunidade Autónoma de Castilla y León está formada por nove províncias, Ávila, Burgos, León, Palencia, Salamanca, Segovia, Soria, Valladolid e Zamora, desde a aprovação do Estatuto de Autonomia, em 1981 (Figura 1).

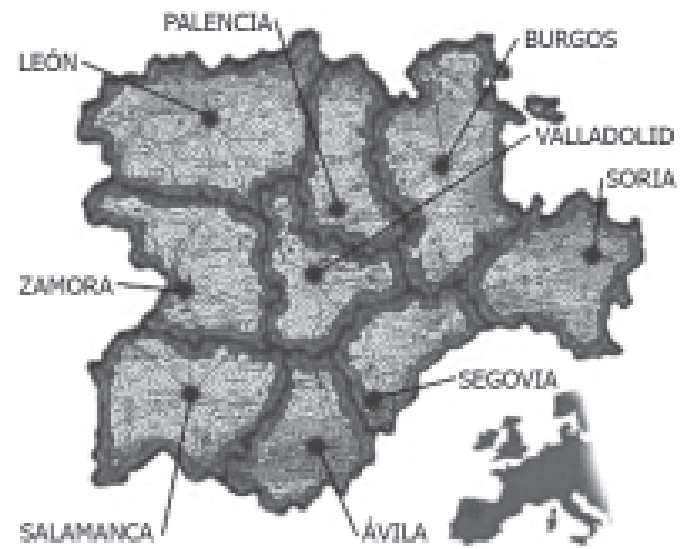

Fig. 1 - Mapa de Castilla y León e seu referente Europeu.

Uma das principais características de Castilla y León é sua grande extensão geográfica, quase $95.000 \mathrm{Km}^{2}$ sendo uma das regiões mais grandes não somente da Espanha, mas da Europa. Isto em claro contraste com sua escasa população, apenas 2.500.000 habitantes (Valdeón 1996: 36-38). $A$ isto se acrescenta um forte envelhecimento da população. Embora, haja uma tendência ao equilíbrio frente a décadas anteriores, pois a população não tem descendido de forma marcante, por causa dos baixos índices de mortalidade e a menor incidência da emigração. A isto se acrescentam os efeitos da imigração que acontecem nesta comunidade, como também no resto do país.

Sob o ponto de vista econômico, a relevância da agricultura tradicional está diminuindo frente às pequenas empresas e ao setor serviços. 0 turismo, principalmente 0 turismo cultural, tem um papel protagonista desde meados da década dos 90. A incorporação de Espanha à Comunidade Européia tem tido uma grande influência na economia castellano-leonesa, especialmente no âmbito do patrimônio, através de programas de financiamento europeu, entre cujos objetivos encontra-se o desenvolvimento de zonas rurais oferecendo ajudas a iniciativas que contribuam ao aprimoramento social e econômico de zonas desfavorecidas, criando emprego e promovendo a fixação da população nas ditas áreas.

Levando em consideração a riqueza e variedade de sítios de Castilla y León, era possível ter realizado um estudo mais detaIhado de algum exemplo significativo. No entanto, o objetivo era poder oferecer tanto uma visão de conjunto, quanto a posibilidade de comparação com outros casos, mais que incidir na singularidade, no caráter de unicum de algum destes sítios. Neste sentido, a proposta de análise dos discuros não é um análise de conteúdo stricto sensu, entendido como o estudo detalhado quantitativo e qualitativo das mensagens a partir do discurso divulgativo concreto de todos e cada um dos espaços divulgativos que integram a amostra, ou de algum deles, também não é uma "receita pronta" de projeto de divulgação do patrimônio arqueológico.

O objetivo não era esse, não se pretendia conhecer como se divulga um determinado tema, às vezes recorrente, mas aprofundar o conhecimento sobre as práticas divulgativas aqui e agora, atendendo ao que se diz, o que se faz e o que deveria ser feito. Toma-se para isso os discursos como objeto de estudo, tratados no seu sentido mais amplo, como concepção sobre um campo concreto, neste caso a divulgação, que articula tanto textos quanto espaços e ações. Dado que a disciplina arqueológica amplia suas áreas de atuação e neste sentido a divulgação é uma parte fundamental, também precisa ser objeto de pesquisa como os outros temas até agora prioritários, o que justifica uma pesquisa deste tipo. 
Ante a falta de um quadro de referência único se recorreu a elementos procedentes de diferentes disciplinas. Com efeito, é problemático definir como museológica, arqueológica, turística, sociológica ou antropológica esta pesquisa, mesmo que pela temática, pelos aspetos que são tratados, pelas experiências prévias inspiradoras e pela metodologia, responda, de alguma maneira, a todas elas, embora não seja de forma pura. Optou-se pela permeabilidade disciplinar que se considerou mais operativa que o bloqueio ante a falta de uma etiquete adequada. Mesmo arriscando não reunir stricto sensu as características mais ortodoxas dos estudos-tipo de tais disciplinas. Era esta a alternativa para poder realizar uma pesquisa que desse resposta às perguntas feitas: Como se divulga na prática? Houve uma transformação nos discursos, ou são apenas mudanças formais conforme a uma política favorável à divulgação?

Esta pesquisa procurava contribuir ao avanço do conhecimento na disciplina arqueológica tomando como objeto de reflexão um âmbito, o da divulgação, o qual no momento atual não tem atingido o patamar de debate e o grau de amadurecimento alcançado já em outros âmbitos. Finalmente, colocar os discursos como centro de atenção deslocando ao patrimônio arqueológico propriamente, supunha a introdução de um novo olhar, no qual a comunicação tem uma grande relevância. Entra aqui em jogo a dimensão pessoal, subjetiva e qualitativa.

\section{Algumas considerações teórico- metodológicas prévias}

Sob o ponto de vista teórico, embora seja difícil uma adscripção definitiva, esta pesquisa não pode se desligar das teorias pos-processuais, inclusive do que autores como Hodder (1999: 5) chamam de pos-posprocessuais. Não se pretendia um seguimento estrito de suas idéias. Também não se pretendia realizar uma pesquisa de profun- da carga teórica, nem atacar os alicerces da prática arqueológica processual. Embora, é claro, que o tipo de temas dos quais se trata, os discursos e a ênfase em determinados aspectos, como a dimensão social da disciplina enquadram-se nesta linha de pensamento das ciências sociais, não apenas arqueológica. Nela a subjetividade, a relevância da eleição pessoal e o pluralismo têm um claro protagonismo. Neste sentido, as experiências tanto do âmbito anglo-saxão (Colley 2000, McManamom e Hatton 2000) quanto da América do Sul (Funari, Neves e Podgorny 1999) têm sido influências marcantes. Um tema como este e tratado sob este olhar somente era possível neste quadro teórico de referência.

No que diz respeito à metodologia, a opção pela etnografia tem sido uma decisão de caráter operativo. Embora possa se considerar uma aplicação heterodoxa, assumiuse o olhar antropológico (Jociles 1999a: 8) e as técnicas de pesquisa próprias da etnografia. No entanto a aplicação destas técnicas, a análise do discurso (Jociles 2000), as entrevistas (Sanmartín 2000) e a observação participante (J ociles 1999b) são uma versão mais leve a respeito ao ideal proposto. No caso concreto dos espaços divulgativos, a coleta de informação in situ foi completada com a aplicação das outras técnicas de pesquisa na abordagem de alguns aspectos da pesquisa que não são o objeto deste artigo. Como são os discursos dos agentes da divulgação, entre eles os diretores de museus, empresas de arqueologia, servidores públicos da área de arqueologia e pesquisadores, assim como a analise dos discursos de diferentes tipos de materiais divulgativos, guias arqueológicos, folders e outros (Mansilla 2005) e dos discursos do público que visita esses espaços divulgativos. É, pois, uma metodologia imperfeita, suscetível de aprimoramento que poderá ser concretizada em próximas pesquisas. Embora não seja a metodologia ótima, tem sido operativa, partindo de experiências diversas, de clara orientação antropológica, que permitiram realizar a análise 
dos conjuntos discursivos e atingir conclusões válidas.

\section{ANALISE}

Segue-se a análise dos discursos dos espaços divulgativos, museus, sítios arqueológicos e aulas arqueológicas. É este o tipo de discurso que têm uma maior incidência no público ou uma maior visibilidade. 0 que se denominou discurso dos lugares é um conjunto amplo e complexo, formado por uma amostra que se considerou suficientemente representativa. Tanto sob o ponto de vista quantitativo (10 museus, entre os quais estão inclusos aqueles que têm seções de arqueologia e os estritamente arqueológicos, 36 sítios arqueológicos e 23 aulas arqueológicas), quanto qualtitativo, ao incluir na amostra os exemplos mais significativos das diferentes províncias. No entanto, levando em consideração o caráter dinâmico da divulgação, no momento de fechar a pesquisa abriram-se e, com efeito, continuam a ser abertos ao público novos espaços divulgativos que não foram possíveis incluir na análise. No momento atual há mais de trinta aulas abertas (Val e Escribano 2004). São estes os espaços divulgativos mais novos, ubicadas perto dos sítios arqueológicos, em prédios de arquitetura rural ou prédios da comunidade atualmente fora de uso, sendo seus principais objetivos: 1) complementar, embora não substituir, os museus, 2) servir de explicação, preparar e provocar a visita aos sítios e 3) obter rentabilidade social e cultural nos lugares onde a Administração já tinha investido previamente. As aulas arqueológicas se caracterizam por seu pequeno tamanho, o protagonismo dos elementos visuais, auditivos e tácteis e a ausência de um acervo próprio, de serviços associados de conservação, documentação e pesquisa de materiais originais.

Optou-se pela limitação do número das variáveis, mesmo que o potencial de análise fosse muito maior, de forma que fosse possível a comparação entre os diferentes espaços. Assim mesmo, isto obrigava a inclusão de algumas variáveis quantitativas. Cada espaço introduz algumas nuances, mas as variáveis analisadas foram oito. (Figura 2).

\section{Variáveisanalisadas nos discursos dos lugares}

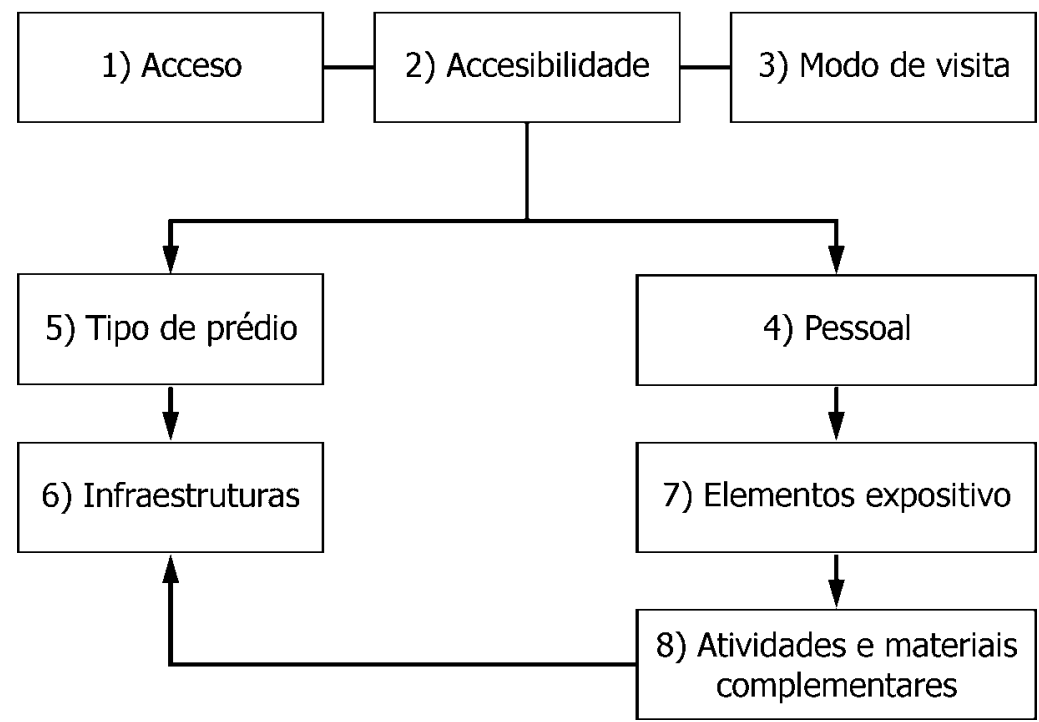

Fig. 2 -Variáveis analisadas nos discursos dos lugares. 
A relação de alguma destas variáveis com o discurso divulgativo pode resultar pouco evidente, como é no caso da acessibilidade (Espinosa 2002a, 2002b) ou das infra-estruturas, que podem nos fazer pensar mais numa simples descrição de que elementos apresentam os diferentes espaços e quais faltam. No entanto, entendendo o término discurso no sensu lato, não estritamente linguístico, tais variáveis são significativas pois estão mostrando uma forma de entender a divulgação, da qual desprende-se uma determinada valorização da experiência e da relação com o público, neste contexto concreto, ambas pouco valorizadas.

Da análise dos discursos dos museus, desprendem-se quatro conclusões:

1. As instalações museográficamente recentes, como as dos Museus de Zamora e Palencia, supuseram uma mudança formal com um maior protagonismo do discurso visual, mas sem que tenha acontecido uma verdadeira transformação do discurso clássico. Este se articula basicamente no entorno de cartazes, vitrines e objetos individualizados. (Figura 3).

2. Sob o ponto de vista das atividades divulgativas, os museus são mais dinâmicos do que erroneamente se pensa. Com efeito, é no Museu de Ávila onde se têm realizado algumas das mais interessantes experiências. Ao mesmo tempo, têm um grande potencial neste sentido pelas suas infraestruturas e acessibilidade, apesar das limitações de pessoal.

3. A falta de estudos de público é uma das grandes carências ainda hoje, tanto nas exposições temporais quanto nas permanentes, indo além dos comentários emotivos e das referências numéricas que

\section{Tipos de discursos expositivos}

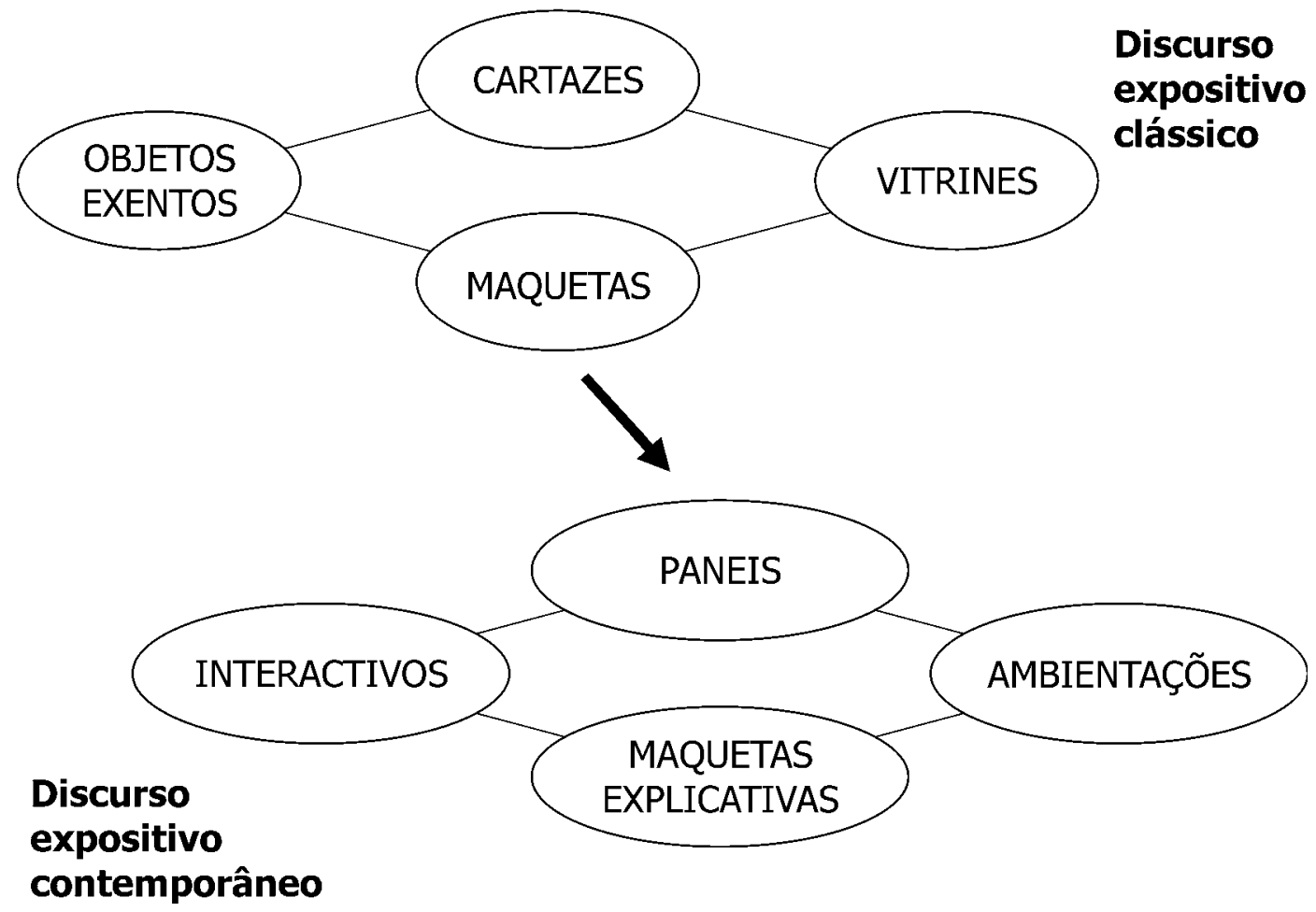

Fig. 3 - Tipos de discursos expositivos. 
são tomados como marcadores do sucesso das exposições (Asensio 1996, Asensio y Pol 2002a, 2002b, 2003, Asensio, Pol, Calderia y Alteria 1999). Neste sentido, o público tem um papel secundário.

4. Faltam, assim mesmo, estudos sobre as relações entre as exposições temporais e a exposição permanente, e seu efeito no público (Kelly 2000), que incidam nas influências que podem ter sobre elas os fatores externos. Principalmente naquelas de maior sucesso como foi o caso de Celtas y Vettones em Ávila (V.AA. 2001) ou Atapuerca un millón de años em Burgos (Bermúdez de Castro, Arsuaga, Carbonell e Rodríguez 1999).

Em relação ao discurso dos sítios arqueológicos, até agora se tem atuado no nível macro, atendendo ao acondicionamento dos sítios, sua conservação e sinalização, no entanto, falta ainda o desenvolvimento do nível micro, isto é, dos detaIhes e da articulação entre os diferentes elementos para atingir uma divulgaçao efetiva, integrando a sinalização, a informação in situ e os materiais complementares. Tem-se incidido principalmente nos cartazes. No entanto, isto não é suficiente, daí que uma boa divulgação nestes espaços passe por:

1. Uma boa informação em todos os âmbitos, frente a situações como a vila romana de Navatejera em León, desconhecida para a maioria dos turistas, apesar de sua proximidade à cidade.

2. Uma oferta adequada aos tipos de público reais, cientes e explicitando que nem todo o público pode ter acesso a determinados sítios. Isto acontece com Ulaca em Ávila, onde as própias condições físicas do sítio numa altura elevada e de difícil acesso restringem as visitas.

3. Uma boa comunicação com o público, através de recursos acessíveis física e inteletualmente.

Levando em consideração que a visita in situ em geral atende a diferentes aspectos como o conhecimento, as experiências e as atitudes, bem como favorece uma melhor aproximação ao patrimônio arqueologico, são quatro os elementos chave que necessitariam ser repensadas e melhor articuladas visando o acondicionamento dos sítios:
1) A paisagem
2) Os restos arqueológicos
3) A própria experiência da visita
4) Os materiais complementares

As aulas arqueológicas, o espaço divulgativo mais novo, embora sua diferente denominação responde de fato à mesma problemática comum aos centros de interpretação. Seu crescimento como instrumento de geração de renda e emprego, bem como de dinamização turística, são objetivos nem sempre atingidos (Mansilla 2004 e e.p., Mateos 2003).

1. Observa-se uma certa uniformidade no que diz respeito ao tipo de discurso textual, embora com algumas diferenças na extensão das unidades textuais, no estilo, no tom e no léxico. Nos diferentes elementos divulgativos das aulas, acontecem as mesmas fraquezas, inclusive na aula soriana de Antiqua Osma, a única que oferece uma visita audio-guiada. De maneira que algumas das características que se observam nos discursos textuais dos cartezes e painéis, encontram-se também nos vídeos. Há unanimidade quanto à importância de reduzir a extensão dos textos e evitar o excesso de termos muito específicos. No entanto, não se pode falar propriamente de um estilo típico da interpretação do patrimônio, mais direto, que chegue aos diferentes tipos de público, que apele aos conhecimentos ou experiências prévios dos visitantes, que provoque 0 interesse, que suscite câmbios de atitude principalmente nas questões relativas à valorização e proteção do patrimônio arqueológico. Não há mensagens diretas deste tipo.

2. No que diz respeito aos conteúdos, as aulas parecem procurar um equilíbrio entre a introdução de novidades formais próprias de um discurso expositivo contemporâneo (Figura 4) e a autoproclamada objetividade baseada nos dados, na pesquisa etc. Não são 


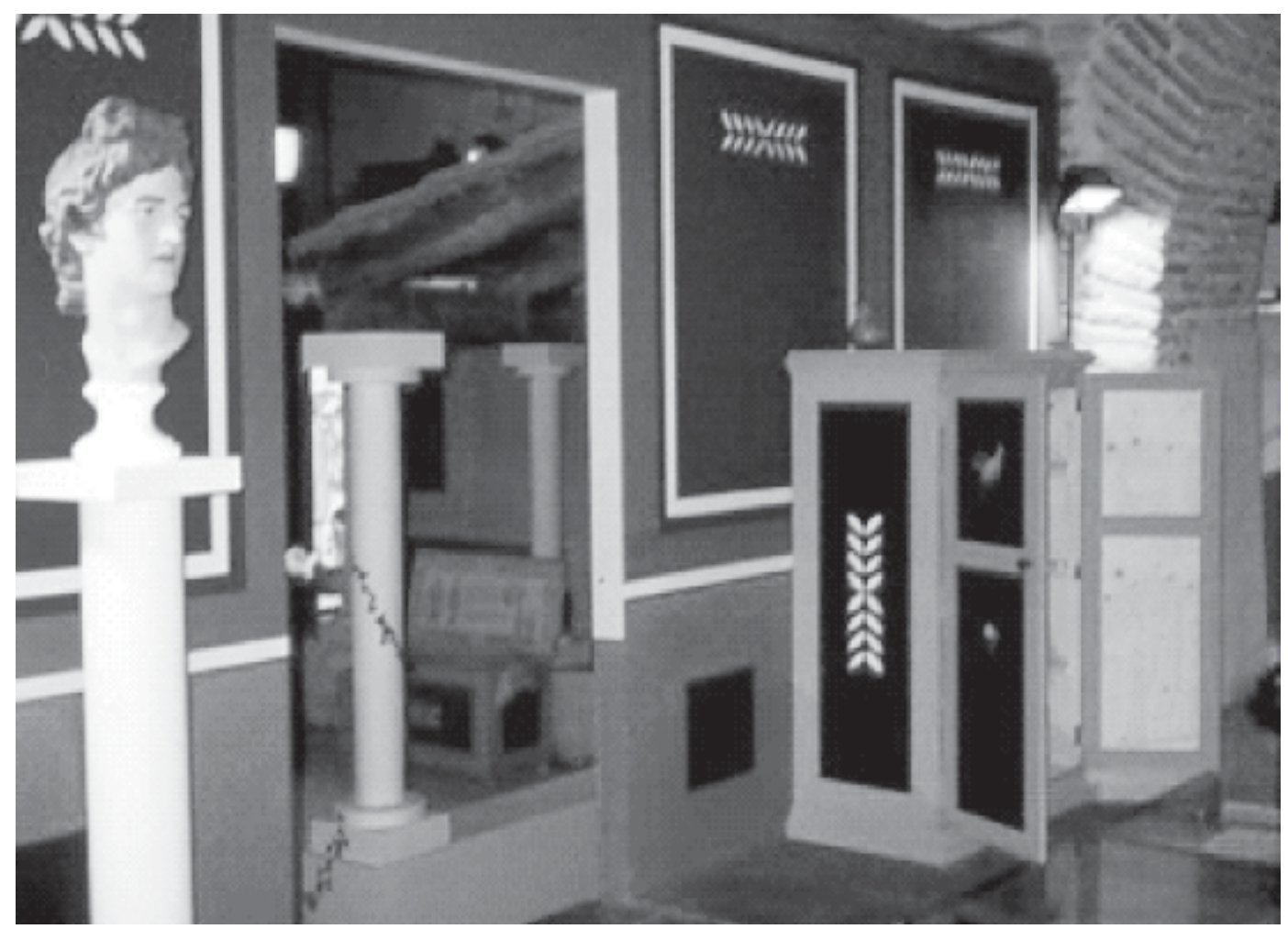

Fig. 4 - Recreação de ambiente romano. Aula Arqueológica Aguilafuente (Segovia)

apresentadas narrativas que resultem significativas para os diferentes públicos. Isto implica um discurso que é muito historicista em alguns casos, no seu sentido mais tradicional e distante, muitas datas e dados, governantes e um mundo masculino de batalhas, detalhe arquitetónico, tático e técnico, que se conecta pouco com a experiência quotidiana do visitante, como se aprecia principalmente nas aulas da rota das fortificações de fronteira em Salamanca, as quais se afastam das atuais linhas de pesquisa da arqueologia histórica de autores como Lydon (1999) ou Funari (1998, 1999) nos seus diferentes contextos. No que diz respeito às expectativas, na maioria dos casos nos quais o visitante não tem uma idéia muito precisa do que vai ver, 0 grau de satisfação é elevado. Pelo contrário, se aprecia uma certa decepção quando as expectativas são maiores, como acontecia na aula dedicada a Atapuerca.
3. A I magem das aulas nao é homogênea, nem sequer nas que formam parte das rotas arqueológicas como a dos Valles de Zamora, e sua articulação com outros espaços divulgativos do patrimônio arqueológico não está muito definida.

4. Falta uma adequada avaliação dos elementos expositivos, fundamentalmente das aportações reais dos elementos mais novedosos frente aos mais tradidionais. Aqui entraria o tão discutido tema da interatividade. (Ramos 2003).

Levando em consideração as características gerais dos discursos nos diferentes espaços, aprecia-se que são mais os elementos partilhados do que as divergências: (Figura 5).

1. Observa-se uma semelhança estrutural entre os diferentes espaços.

2. Existe uma desconexão entre 0 discurso sobre o patrimônio e o papel do pró- 


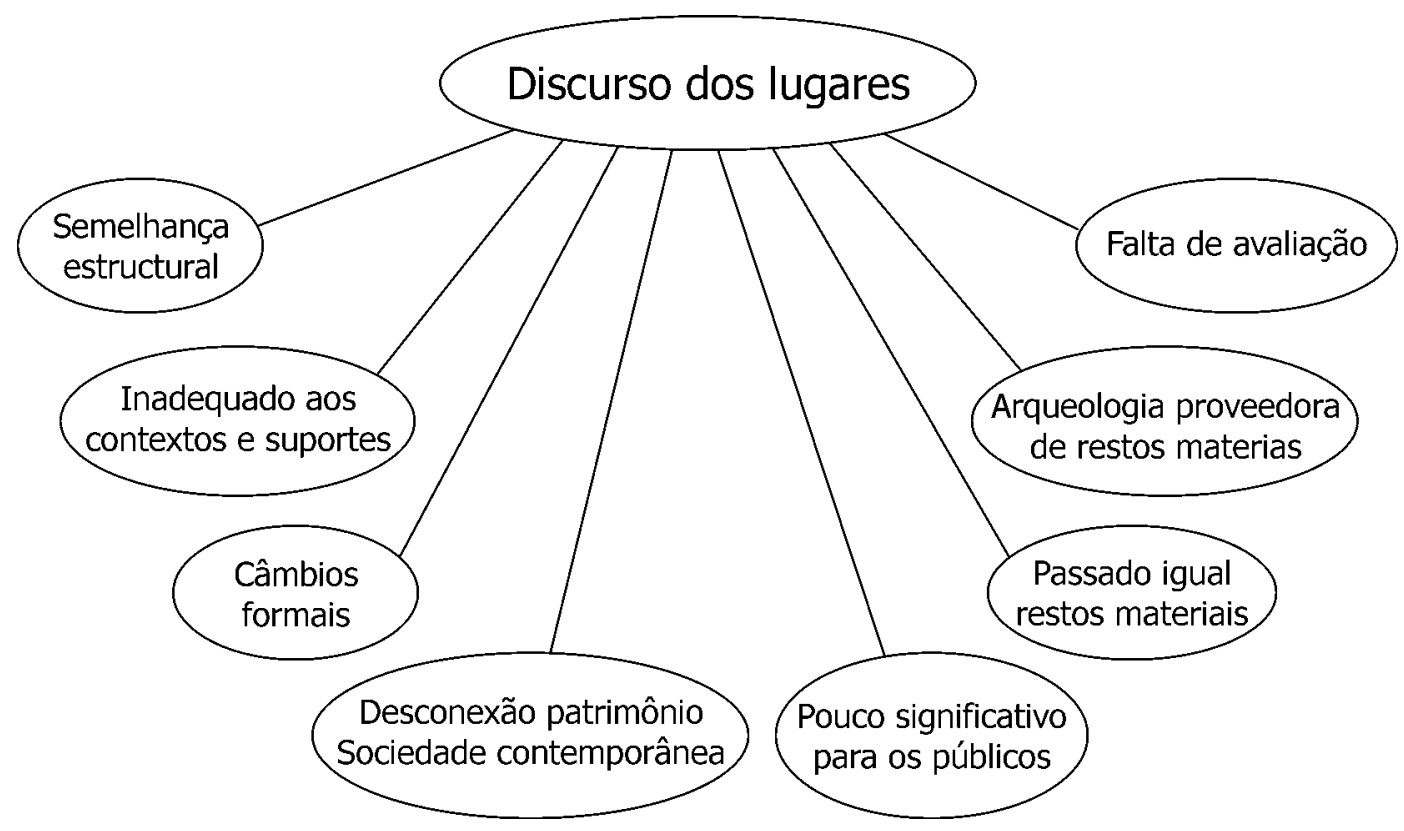

Fig. 5 - Discurso dos lugares.

prio patrimônio, o significado do passado na sociedade contemporânea.

3. Não tem havido uma transformação do discurso divulgativo, que continua sendo demorado no seu estilo e no seu ritmo, carente de hierarquização, com um léxico pouco adequado aos contextos e suportes. Tem-se produzido mudanças formais, com a diversificação dos espaços divulgativos e a introdução de elementos expositivos contemporâneos.

4. Nao se incide no significado nem no sentido dos discursos para os diferentes tipos de público.

5. Transmite-se uma imagem da arqueologia como provedora de restos materiais, no entanto, seus praticantes estão ausentes. Nao há uma mensagem patrimonial explícita.

6. O passado se identifica com os restos materiais, colocando num segundo plano as sociedades.

7. A falta de avaliação e o desconhecimento do público são as duas carências mais destacadas.

\section{CONCLUSÕES E PERSPETI VAS}

Chegados a este ponto, são mais as questões que tem ficado pouco definidas, e também as linhas de pesquisa que ficam abertas com este trabalho, do que as respostas definitivas. Assim, em primeiro lugar, não se estabeleceu uma tipologia clara de discursos divulgativos, o que tem sido mais uma reflexão voltada para os aspectos práticos. Em segundo lugar, não se estabeleceram as representações sociais (I báñez 1988) nem relativas ao patrimônio arqueológico, nem à sua divulgação. De fato, não se definiram quais são as imagens do patrimônio que estão sendo transmitidas ao público. Talvez por serem estas duas questões diferentes, uma o que é o patrimônio e como é trasmitido, e uma outra, como é visto e entendido pelo público. No entanto, uma primeira aproximação a este aspecto foi feita através do estudo piloto sobre o público.

As linhas de pesquisa abertas são multiplas, tanto aprofundando na dimensão horizontal que permita a comparação 
entre diferentes âmbitos geográficos, como na vertical, aprofundando em diversos aspectos quase não tratados. Fundamentalmente na ênfase dos aspectos que mais incidem no fortalecimento das imagens populares sobre o patrimônio arqueológico, as atividades e materiais complementares, os produtos à venda etc. e os mecanismos que intervêm no dito processo. Em definitivo, trata-se de colocar o público em primeiro lugar, assumindo que o processo divulgativo não finaliza na transmissão de determinados conhecimentos. Pelo contrário, estes são re-elaborados ou rejeitados pelo imaginário popular que, ao mesmo tempo, está incidindo na valorização social do patrimônio num sentido ou noutro.

Com respeito à pergunta chave feita inicialmente, até que ponto se tem produzido uma transformação dos discursos divulgativos, ou apenas uma maquialhem formal dos mesmos, as respostas são múltiplas:

1) As mudanças além dos aspetos formais não são tão radicais.

2) Ainda não houve o passo para um discurso propriamente divulgativo.

3) A divulgação do patrimônio arqueológico ainda é um âmbito da arqueologia um pouco difuso.

4) Não se conhecem os diferentes tipos de público.

No entanto, são também numerosas as vias de atuação que se abrem para aprimorar a divulgação, tanto sob o ponto de vista teórico quanto prático. Entre o que se pode considerarcomo propostas teóricas, destacase:

\section{Aanálise dos discursos divulgativos} em outros soportes, Internet, CDs, o que permitiria contrastar até que ponto, em alguns casos, se mantêm algumas das caraterísticas que se encontram em suportes mais tradicionais como são os cartazes, os folders ou as guias.

\section{A autocrítica entre os especialis-} tas em divulgação: a responsabilidade neste âmbito não corresponde apenas a quem fica fora da disciplina.
3. A aproximação ao olhar de outros coletivos, principalmente profissionais da educação, da mídia e do turismo.

4. A análise das imagens patrimoniais populares, para poder estabelecer uma melhor comunicação com o público visando a modificação de idéias erradas e a introdução de outras novas.

Entre as propostas práticas podem ser destacadas:

1. A reorientação da formação, tanto no âmbito formal, universitário, onde com efeito se estão incorporando cursos principalmente de pós-graduação, quanto no campo não formal, através de uma formação continuada com oficinas de tipo prático destinadas às pessoas que estão em contato direto com o público. Isto como uma forma, ao mesmo tempo, de compartilhar experiências e melhorar a qualidade do serviço que oferecem aos visitantes. ${ }^{1}$

2. A potenciação da dimensão pessoal. Sucesso ou fracaso nas experiências dependem muito mais das pessoas do que da dotação de infra-estruturas, como se pode apreciar no caso dos sítios arqueológicos de Numancia (Soria) (Jimeno, Sanz, Benito e Torre 2004) ou Pintia (Valladolid) (Sanz et alii 2003) nos quais, graças ao entusiasmo e perseverância das equipes, conseguem-se resultados muito bons. Neste sentido, é preciso, de uma parte, considerar a divulgação num âmbito no qual os estudantes precisam se formar, e de outro lado, é preciso ampliar o contexto local na incorporação de novos profissionais da divulgação, pois nem sempre é fácil poder contar com esses perfis nas populações pequenas.

3. A imagem que tenho apresentado da situação atual da divulgação do patrimônio arqueológico em Castilla y León, partindo da

(1) É importante destacar o papel da Asociación para la Interpretación del Patrimonio no sentido de aprimorar a qualidade, a formação e a prática da interpretação do Patrimônio. 
analise dos discursos divulgativos, não é uma imagem definitiva. Com certeza nos diferentes aspectos críticos aos que se fez referência, se atenuarão e irão se corrigindo como resultado da própria prática divulgativa. Alguns dos casos analisados se renovarão ou serão completamente substituídos com a introdução de novidades que não foram indicadas.

Também não é a imagem de uma situação única, se considera que tanto as fraque- zas quanto as alternativas propostas não surgem da singularidade das próprias características e da história particular de cada um dos espaços divulgativos. Trata-se mais do resultado da aplicação de uma metodologia de análise que poderia ser extrapolada a outros contextos, com rumos bastante diferentes. Isto permitiria, assim mesmo, meIhorar a definição e o ajuste da mesma para superar as carências que se têm apresentado neste caso concreto.

\begin{abstract}
The interest in archaeological heritage and particularly in its popularisation is a global phenomenon. In Spain it is in the last decades when this occurs. This paper analyses the case of one Autonomous Community, Castilla y León, which is characterized by the richness and diversity of its heritage. The main focus of this paper is the discursive dimension of the different popularisation places, museums, archaeological sites and interpretation centres, in order to evaluate their characteristics and their inter-relations. Emphasizing the week points and theoretical and practical alternatives.
\end{abstract}

Key words: archaeological heritage - popularization - Spain - Castilla y León

\title{
Bibliografia
}

ASENSIO, M.

1996 Seminario Internacional Museum Visitor Studies. Mérida.

2000 "Estudios de público y evaluación de exposiciones como metodología de planificación museológica: el caso del Museu Marítim de Barcelona". Museo, 5: 73-104.

ASENSIO, M. E POL, E.

2002a Nuevos escenarios en educación. Aprendizaje informal sobre el patrimonio, los museos y la ciudad. Buenos Aires. Aique.

2002b “¿Para qué sirven hoy los estudios de público en museos?" Revista de Museología, 24-25: 11-20.

2003 "Aprender en el museo". Em Iber. Didáctica de las Ciencias Sociales Geografía e Historia, 36: 62-77.

ASENSIO, M.; POL, E.; CALDERIA, P. E ALTERI, J.

1999 "Los programas públicos: evaluación de problemas y diseño de soluciones". Em Revista de Museología, 16: 79-83.

BALLART HERNÁNDEZ, J.

1997 El patrimonio histórico y arqueológico: valor y uso. Barcelona. Ariel.

2002 "La formación de los museólogos. Balance y expectativas de una mirada académica". Em Revista de Museología, 24-25: 11-18.

BALLART HERNÁNDEZ, J. E JUAN I TRESSERRAS, J.

2001 Gestión del patrimonio cultural. Barcelona. Ariel.

BERMÚDEZ DE CASTRO, J.M.; ARSUAGA, J.L.; CARBONELL, E. E RODRÍGUEZ, J.

1999 Atapuerca. Nuestros antecesores. Valladolid. Junta de Castilla y León. CSIC. Fundación del Patrimonio Histórico de Castilla y León.

COLLEY, S.

2002 Uncovering Australia. Archaeology, 
indigenous and the public. Crows Nest. Allen \& Unwin

ESPINOSA RUIZ, A.

2002a "La accesibilidad física e intelectual de todo tipo de público al patrimonio cultural (I)". Boletín de interpretación, 6: 13-15. http:/ /www.interpretaciondelpatrimonio.com

2002b "La accesibilidad física e intelectual de todo tipo de público al patrimonio cultural (II)". Boletín de interpretación, 7: 4-6. http:// www.interpretaciondelpatrimonio.com

FUNARI, P.P.A.

1998 Cultura material e arqueologia histórica. Sâo Paulo. Campinas. UFCH. Colecçâo Idéias.

FUNARI, P.P.A.; HALL, M. Y JONES, S. (EDS.)

1999 Historical archaeology. Back from the edge. Londres. Routledge.

FUNARI, P.P.A.; NEVES, E.G. E PODGORNY, I.

1999 Anais da I Reunião Internacional de Teoria Arqueológica na América do Sul. Revista de Arqueologia e Etnologia. Suplemento 3.

IBÁÑEZ GRACIA, T.

1988 Ideologías de la vida cotidiana. Barcelona. Sendai.

HODDER, I.

1999 The archaeological process. An introduction. Oxford. Blackwell.

JIMENO MARTÍNEZ, A., SANZ ARAGONÉS, A., BENITO BATANERO, J.P. E TORRE ECHEVARRI, J.I. DE LA

2004 "Numancia: conocimiento y difusión del pasado". Em J. del Val Recio eC. Escribano Velasco (eds.): Actas. Puesta en valor del Patrimonio Arqueológico en Castilla y León. Salamanca. Junta de Castilla y León: 247264.

JOCILES, M.I.

1999a "Las técnicas de investigación en antropología: mirada antropológica y proceso etnográfico". Em Gazeta de Antropología, 15: 1-35. http:// www.ugr.es/ pwlac/

1999b "Observación participante y distancia antropológica". Em Revista de Dialectología y Tradiciones Populares, LIV. Cuaderno segundo: 1-40.

2000a "El análisis del discurso: de cómo utilizar desde la antropología social la propuesta analítica de Jesús Ibáñez". Em Ateneo de Antropología, 0: 1-18. (Actualizado el 13/ 2/00) http://www.ucm.es/info/dptoants/ ateneo/start.html

KELLY, L.

2000b "Making a difference: what have we learned about visitor learning?" Sydney.
Australian Museum Audience Research Centre. http://www.amonline.net.au/ amarc/research/learning-htm-web.pdf

LYDON, J.

1999 "Pidgin English: historical archaeology, cultural exchange and the chines in The Rocks, 1890-1930". Em P.P.A. Funari, M. Hall e S. J ones (eds.): Historical Archaeology: back from the edge. Londres. Routledge: 255-283.

MANSILLA CASTAÑO, A.M.

2004 "Aulas arqueológicas en Castilla y León: ¿una nueva denominación de origen?". Em Boletín de Interpretación, 11: 14-15. http:/ / www.interpretaciondelpatrimonio.com

2005 "Las postales: ¿un instrumento de la divulgación del patrimonio arqueológico?. Em Pasos. Revista de Turismo y Patrimonio Cultural, 3(2): 257-263. www. pasosonline.org

(e.p.) "La divulgación del patrimonio arqueológico en Castilla y León a través de las aulas arqueológicas: una visión de conjunto."Em Actas de las VIII Jornadas Andaluzas de Difusión del Patrimonio: La interpretación del patrimonio: redes, rutas y centros de interpretación. Almería 22-24 de febrero de 2005.

MCMANAMON, F.P. E HATTON, A. (EDS.)

2000 Cultural Resource Management in contemporary society. Perspectives on managing and presenting the past. Londres. Routledge.

MATEOS RUSILLO, S.

2003 "El peligroso éxito de los centros de interpretación. Una amenaza para la interpretación del patrimonio en España." Em Boletín de Interpretación, 8: 7-9. http:/ /www.interpretaciondelpatrimonio.com

RAMOS, F.

2003 “iNo me toquen los...botones!” Em Boletín de Interpretación, 8: 16-18. http:// www.interpretaciondelpatrimonio.com

SANMARTÍN ARCE, R.

2000 "La entrevista en el trabajo de campo". Revista de Antropología Social, 9: 105-126.

SANZ MÍNGUEZ, C.; VELASCO VÁZQUEZ, J .; CENTENO CEA, I.; GALLARDO MIGUEL, MaA. E GARRIDO BLÁZQUEZ, A.I.

2003 "El Centro de Estudios Vacceos "Federico Wattemberg" y el proyecto Pintia. Bases para la protección, investigación y divulgación del patrimonio cultural vacceo". Em C. Sanz Mínguez y J. Velasco Vázquez (eds.): Pintia. Un oppidum en los confines orientales de la región vaccea. Investigaciones arqueológicas vacceas (1993-2003). Valladolid. Universidad de Valladolid: 251-278 
Revista Arqueologia Pública, São Paulo, № 1, 2006.

VAL RECIO, J. DEL E ESCRIBANO VELASCO, C. 2004 Guía de lugares arqueológicos de Castilla y León. Salamanca. Junta de Castilla y León. VALDEÓN, J.

1996 "De la transición a la Autonomía". En A. García Simón e J. Ortega Valcárcel (eds.):
Historia de una cultura IV. Castilla y León/ Informe. Valladolid. Junta de Castilla y León: 10-39.

VV.AA.

2001 Celtas y vettones. Ávila. Diputación Provincial de Ávila. 